\title{
EVALUATION OF INTEGRATED MULTIMEDIA TRAFFIC OVER ATM NETWORK
}

\author{
Ehab Aziz Khalil \\ Department of Computer Science \& Engineering, Faculty of Electronics Engineering, \\ Menoufiya University, Menouf-32952, EGYPT
}

\begin{abstract}
Virtual Path (VP) provisioning has gained wide acceptance as an effective resource management technique for improving transmission efficiency in ATM network. In our study the VP in the ring is defined as pair for each node, which reassigned a duplex VP. The VP is used in the point-to-point VP Add-Drop multiplexing (VP$A D M)$ scheme carries VC between the same two ring nodes. The physical route assignment for the VP depends on the type (unidirectional/bi-directional) of the considered SONET ring. The main goal of using ADM design is to minimize the cost of evolution from the previous SONET ADM's to ATM ADM's. The performance evaluation of integration video, voice, and data on the proposed VP-Based ATM Ring network has been studied. A suggested control method provides fairness among the traffics, and confirms its effectiveness for integrating of multimedia traffic over ATM network.
\end{abstract}

\section{KEYWORDS}

VP-Based Ring ATM network, integration of video, voice and data traffics, Control method.

\section{INTRODUCTION}

The Broadband integrated Services Digital Network (B-ISDN) is intended to meet the transport needs of the future. It will provide an integrated high speed service for all types of traffic-image, graphics, data, telephony, broadcast TV, and interactive video. All applications and interactive multimedia in particular, will benefit from a single network that can provide the required quality of service (QoS). These networks will use digital switching and transmission, and ATM is the chosen technology [1,2]. ATM networks have the capability to provide a wide range of services and guarantee various end-toend QoS [3]. The basic transmission unit for ATM is a cell with 53 bytes. Each cell with a fixed length simplifies the process of segmentation and reassembly. When the cell routes through a switch node, Virtual Path Identifier (VPI) and Virtual Channel Identifier (VCI) in the cell header are used for looking up switching tables to quickly decide the output VPI, VCI, and port number for completion of switching. Several Virtual Paths (VPs) and Virtual Channels (VCs) can be multiplexed to share a link bandwidth. By fast switching technology and flexible multiplexing, ATM has the advantages of both circuit switching and packet switching. One important characteristic of ATM network is that the ATM networks support various services types to meet application with different QoS [4-45]. This paper investigates the performance of the ATM ring network for carrying multimedia (video, voice, and data) traffic.

\section{The Proposed NeTwork}

The proposed network is a VP-Based ATM Ring Network based on a ring topology modified to the architecture in [46]. In our study the VP in the ring is defined as pair for each node, which reassigned a duplex VP. Figure 1 illustrates (Synchronous Optical NETwork) SONET/ATM Ring Architecture using point-to-point VP's (denoted by SARPVP). The VP is used in the point-to-point VP Add-Drop 
International Journal of Engineering Sciences \& Emerging Technologies, Feb 2012. ISSN: 2231 - 6604 doi: 10.7323/ijeset/v1_i2_13 Volume 1, Issue 2, pp: 108-117 OIJESET

multiplexing (VP-ADM) scheme carries VC between the same two ring nodes. As mentioned in the VP-Based architecture, each ring's node pair is reassigned a duplex VP. For example, from Figure 1, VP\#2 and VP\#2 (not shown in the Figure) carry all VCs from Node 1 to 3 and from Node 3 to Node 1 respectively. The physical route assignment for the VP depends on the type (unidirectional/bidirectional) of the considered SONET ring.

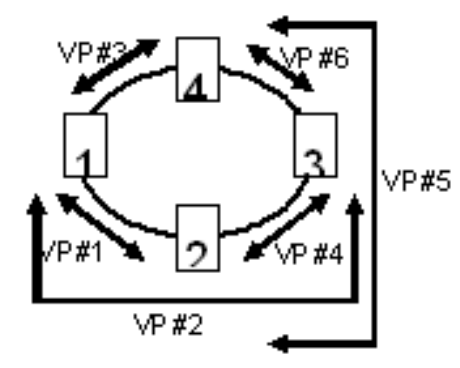

Figure 1 VP-Based ATM Ring network.

In a unidirectional ring, two diverse routes which form a circle are assigned to each VP as shown in Figure 1. Two physical routes 1-2-3 and 3-4-1 are assigned to VP\#2 and VP\#2' (not shown in the Figure). In a bi-directional, only one route is assigned to each duplex VP (e.g., route 1-2-3 is assigned to both the VP\#2 and VP\#2'), and demands between Node 1 and 3 are routed through Route 1-2-3 bidirectional for more details on SONET unidirectional and bi-directional ring architecture see $[47,48]$. In order to avoid the VP translation at intermediate ring nodes of VP connection, the VPI value is assigned on a global basis. The ATM cell add-drop or pass-through at each ring node is performed by checking the cell's VPI value. Since the VPI value has global significance and only one route is available for all outgoing cells. It need not be translated at each intermediate ring node. Thus no VP cross-connect capability is needed for the ATM ADM of this SARPVP ring architecture. The global VPI value assignment presents no problem here, since only one route exists for all outgoing ATM cells. The number of nodes supported by a ring is usually limited to 91 nodes depending on VP field size in bits. If the point-to-point VP ring is used to support present traffic such as Digital Signal type 1 (DS1) services (via circuit emulation), each DS1 comprises a VC connection and is assigned a VPI/VCI based on its addressing information and the relative position of the DS1 within all the DS1's terminating at the same source and destination on the ring. For example, VPI=2 and VCI=3 represents DS1 that is the third DS1 of the DS1 group terminating at Node 1 \& Node 3.

\section{A. Routing in the VP-Based ATM Ring Network}

As mentioned above, the physical route assignment for the VP depends upon the type (unidirectional or bi-directional) of the considered SONET ring. VPI on the node defines it either transit node, which just pass the cells to the next node, or terminated node, which just drop the coming cells, according to the value of VPI. Each node has VPI value for each node else, and no two VPIs have the same value in the same network. Figure 2 illustrates the two types (unidirectional and bi-directional) of SONET Ring. So, the solid line alone indicates the unidirectional type, meanwhile both solid and dotted lines indicate the bi-directional type. In the unidirectional SONET ring, for $\mathrm{N}$ nodes, the maximum number of physical hops is (N-1). For example, node 1 transmits cells to node 2 via the route $1-2$ and node 2 transmits cells to node 1 via route $2-3-\ldots-\mathrm{N}-1$. Obviously that the route in the reverse direction is longer than that in the forward direction, resulting in the required time between the pair conversation is not equal. In the Bi-directional SONET ring, for $\mathrm{N}$ nodes, the maximum number of physical hops is $|\mathrm{N} / 2|$. So for forward direction the path is represented as $(1-2-3-\ldots-\mathrm{N})$, and for reverse direction the path is represented as (N-(N-1)-..-3-2-1). If the value of $\mathrm{N}$ is odd, the number of VPIs for both forward and reverse directions are equal. Meanwhile, if the value of $\mathrm{N}$ is even, the number of VPIs in forward direction is more than the number of VPIs in reverse direction by one. Table 1 shows functions to determine the direction and the number of hops to send cell from source to destination. It is to be noted here that the queue for each direction makes the bi-directional SONET Ring work like two separately unidirectional SONET Ring. The following results in the unidirectional case. To be in bi-directional the number of sources is the duple of the number of sources in the case of unidirectional. 
International Journal of Engineering Sciences \& Emerging Technologies, Feb 2012. ISSN: 2231 - 6604 doi: 10.7323/ijeset/v1_i2_13 Volume 1, Issue 2, pp: 108-117 CIJESET

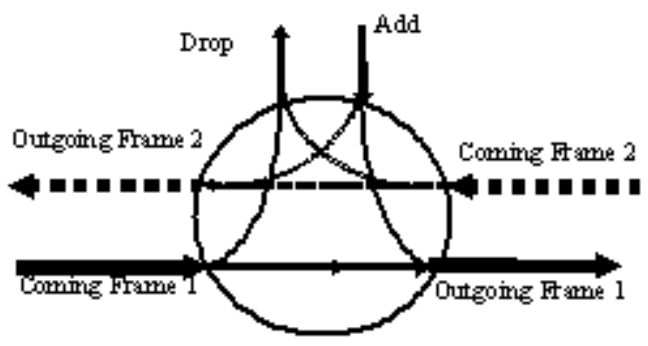

Figure 2 ATM/ADM Node

Table 1

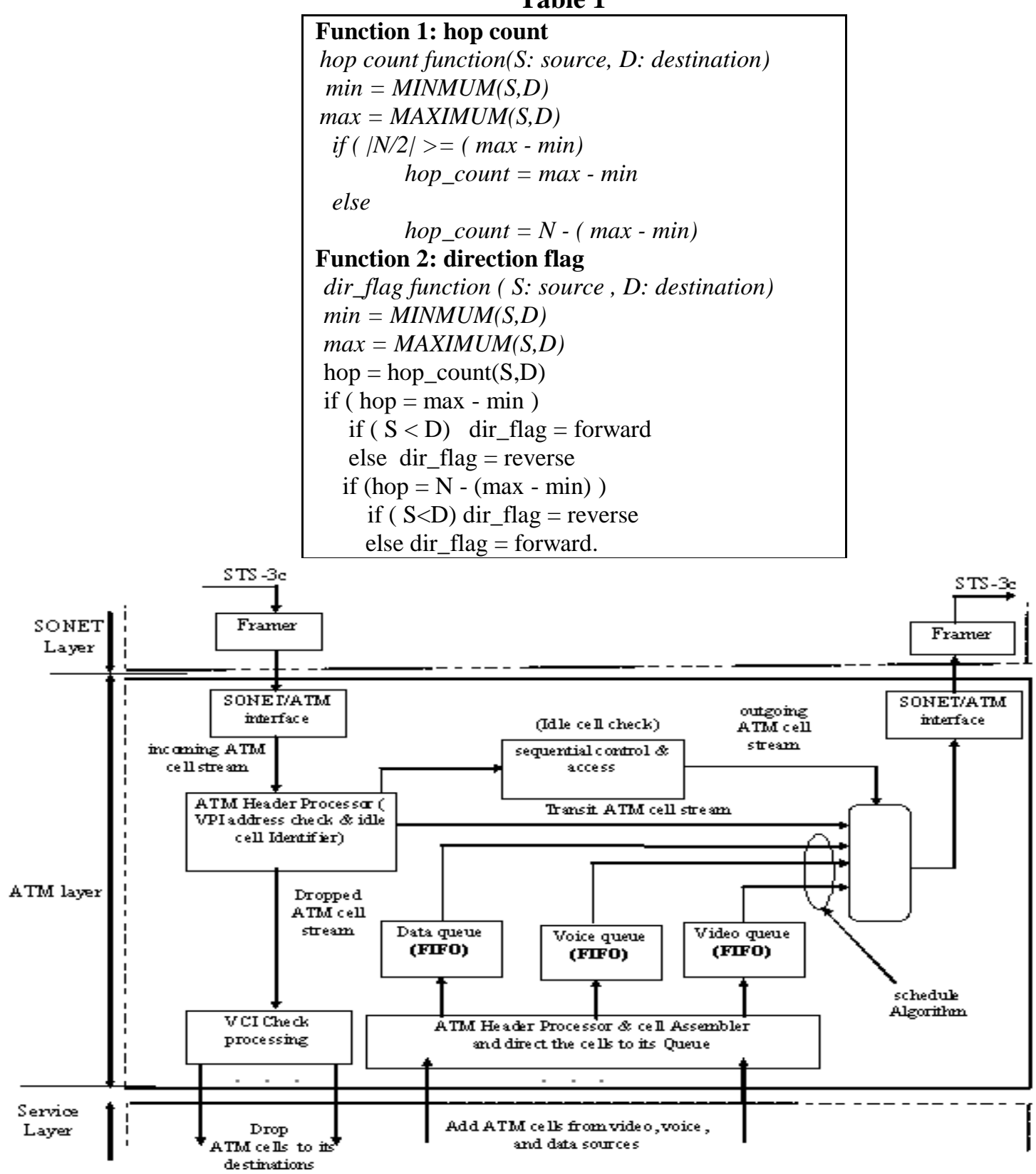

Figure 3 An STS-3c Add-Drop Hardware Configuration

\section{B ATM Add-Drop Multiplexer (ADM) for VP-Based Ring}

A possible Add-Drop Multiplexer (ADM) design for the VP-Based ATM Ring implementation is shown in Figure 3. The main goal of this ADM design is to minimize the cost of evolution from the 
International Journal of Engineering Sciences \& Emerging Technologies, Feb 2012. ISSN: 2231 - 6604 doi: 10.7323/ijeset/v1_i2_13 Volume 1, Issue 2, pp: 108-117 CIJESET

previous SONET ADM's to ATM ADM's. The ATM ADM for the SARPVP architecture can be implemented in different ways depending on physical SONET STS-Nc terminations. The most commonly proposed ATM SNc terminationare STS-3c, STS-12c, and STS-48c [46]. The ADM configuration with STS-3c terminations for a VP-Based ATM Ring implementation supports lowerlevel digital signals (DS1, DS2, AND ITU-T standards) services via circuit emulation $[46,49]$. The ATM VP add-drop function which is performed at the STS-3c level requires three major modules. The first module is the ATM/SONET interface, which converts the STS-3c payload to an ATM cell stream and vice versa. The functions performed in this module include all delineation, self synchronization, and scrambling. The scramble process here is to increase the security and robustness of the cell delineation process against malicious users or unintended simulations of a cell header followed by a correct Header Error Control (HEC) in the information field. The second module is to perform header processing, which includes cell addressing (VPI in this case) and HEC. In order to perform cell add-drop/pass-through, this module checks VPI value of each cell to determine if it should be dropped or passed through. This module also identifies idle cells which can be used to insert cells from the considered office (i.e. signal adding) via a simple sequential access protocol. This sequential access protocol can be implemented by the third module that passes through each nonidle cell and inserts the added cells from each queues into outgoing idle cells in a sequential order. The third functional module includes a service lower-level digital signal card based on VPI/VCI values of ATM cells. This service mapping module first de-multiplexes all ATM cells from STS-3c payload and then drops ATM cells to its destinations according to the VCI values.

\section{C The Proposed Control Method to Allocate Cells}

There are some drawbacks with the proposed control method in [50], in which when the offered load of the data traffic is higher than the video and voice traffics, unfairness among the traffics is involved, that is because the ratios among the traffics are fixed and the offered load of each traffic along with the time is not fixed. In our proposed control method [51], we tackle the unfairness problem between the whole traffic, that is by counting the number of cells from the queue which corresponding to each offered load by the following steps: 1) Assume that the ratios of video, voice, and data traffics are M: N: D respectively. These ratios are supposed to fill up a complete transmission frame. 2) For fairness services between the traffics we have to follow the following steps:

(a) Get $\operatorname{Min}_{o l}$ (Minimum offered load of all the applied traffics).

(b) Set $\mathrm{M}=\frac{\text { videoofferedload }}{\text { Minol }}$.

(c) Set $\mathrm{N}=\frac{\text { voiceofferedload }}{\text { Minol }}$

(d) Set D $=\frac{\text { dataofferedload }}{\text { Minol }}$.

The above mentioned proposed control method tackled the problem of fairness between the traffics. For example, suppose that the offered load of each traffic are the same $0.333,0.333$, and 0.333 this means that the ratio will be $1: 1: 1$, but if the offered load is different as $(0.60,0.30,0.10)$, this means the ratio will be $6: 3: 1$, and vice versa.

\section{Traffic MOdeL}

\section{3-A Video Traffic}

The video traffic is defined as the number of sources $\left(\mathrm{N}_{v i}\right)$ and video encoding rate $\left(\mathrm{R}_{\mathrm{vi}}\right)$. We have considered that video stream are encoded according to a coding standard such as H.261[52] or MPEG [53]. Figure 4 shows the block diagram of a station which encodes and sends a video stream over an ATM network. A frame is taken in the video camera, and sent as an analog signal to the frame grabber, where it is digitized, then it is compressed by the encoder. The data produced by the encoder is passed to the host computer. The host computer pocketsize the encoded video stream, and sends it over the network [53]. 


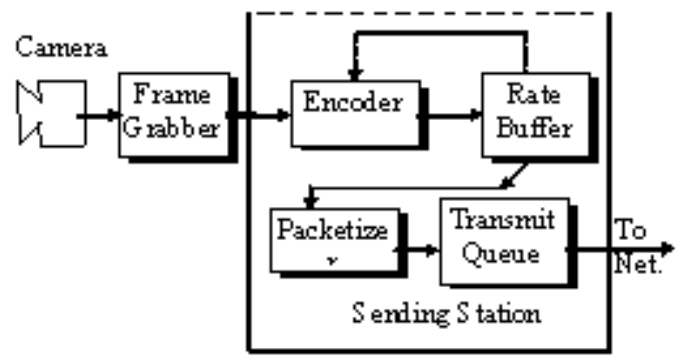

Figure 4 Block Diagram of a Station which Encodes and Sends a Video Stream.

A delay constraint comes from the need to support interactive communications, it is a well known fact that human beings can tolerate up to $200-250 \mathrm{~ms}$ of delay in two-way conversation. In a communications system using compressed video, there are delays both in the encoder and in the decoder that can be as high as $100 \mathrm{~ms}$, as well as delays in the local networks to which the video stations are attached [54]. Therefore, a reasonable constraint for the wide-area component of the delay would be $40 \mathrm{~ms}$. In our study, the video encoding rate is a fixed data rate of $1.5 \mathrm{Mbps}$.

\section{B Voice Traffic}

The voice source is modeled as shown in Figure 5. The voice cell delay time of end-to-end have to be in the range of 250-600 ms. Figure 5 demonstrates the connection of voice sources to the ATM network. At each voice source, a continuous time, analog signal is digitized by a coder [55]. The generated samples are accumulated in a packetizer. When the number of samples in the packetizer reaches the pre-determined cell length, header is attached and an voice cell is generated. The voice cell generation process may be synchronized to an external timing.

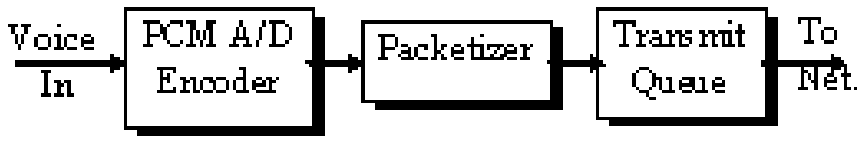

Figure 5 Block Diagram of a Station which Encodes and Sends a Voice Stream.

The generated cells are stored in the transmit buffer in the order of their generation waiting for transmission. Note that, in some LAN, the voice samples are transmitted directly using an assigned TDM channel on the network. In most other LAN protocols, the voice is transmitted in the form of packets where each packet consists of a number of voice samples within a packetization interval [56]. The information from a single voice source can be divided into voiced and unvoiced periods. In the voiced period, a cell is generated when the information for a cell is ready. In the unvoiced period, the cell is generated as an empty cell without information which will be deleted at the user-network interface. and we can also say that the voiced period is talkspurt and unvoiced period is silent period. Each period is approximated by an exponential distribution of means $1 / \alpha$ and $1 / \beta$ s respectively. Let $\mathrm{T}$ be the cell interarrival time, then the average arrival rate per source ( $\mathrm{S}$ in cells/sec) is given by the equation (4).

$$
\mathrm{S}=\frac{1 / \alpha}{T(1 / \alpha+1 / \beta)} \text {. }
$$

It is noted that the randomness introduced by replacing the deterministic time by an exponential one. The first burstness parameters was set $1 / \alpha=352 \mathrm{~ms}$ and $1 / \beta=650 \mathrm{~ms}$ which corresponds to a 35 $\%$ activity factor [57]. We have assumed that, all the voice sources has the same talk period at the same time in the worst case the offered load is talk periods.

\section{C Data Traffic}

The data traffic is defined as message size $\left(\mathrm{M}_{\text {siz }}\right)$ in cells and mean interarrival time $(\mu)$. We selected a fixed $\mathrm{M}_{\mathrm{siz}}$, and interarrival time has an exponential distribution with mean value of $5 \mathrm{~ms}$. We suppose that the data traffic is a message arrived in specified duration. The message comes in instant (in the case of heavy load sometimes during the transmission of long message which takes more than 
International Journal of Engineering Sciences \& Emerging Technologies, Feb 2012. ISSN: 2231 - 6604 doi: 10.7323/ijeset/v1_i2_13 Volume 1, Issue 2, pp: 108-117 CIJESET

the specified duration another message arrives) of times is sent through the network. It is to be mentioned here that the data traffic can arrive to the destination with a long delay time since the data traffic slightly effects with the long delay.

\section{RESUlTS AND DisCUSSION}

\section{A Simulator Check Point}

We have considered that the network consists of a single ATM ring ADM video, voice, and data traffics. The transmission frame is fixed at 44 cells as payload depending on the channel speed at 155.52 Mbps according to the SONET standard. Simulation check point is presented here by adjusting the simulation model closed to the analytical model, the service time assumed as effective service time $(0.0625 \mathrm{~ms})$ as shown in Figure 6.

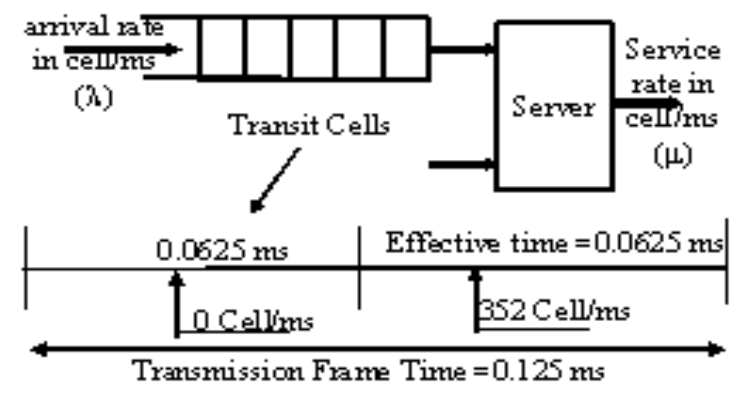

Figure 6 Simulation Queue Model for ADM/ATM Node

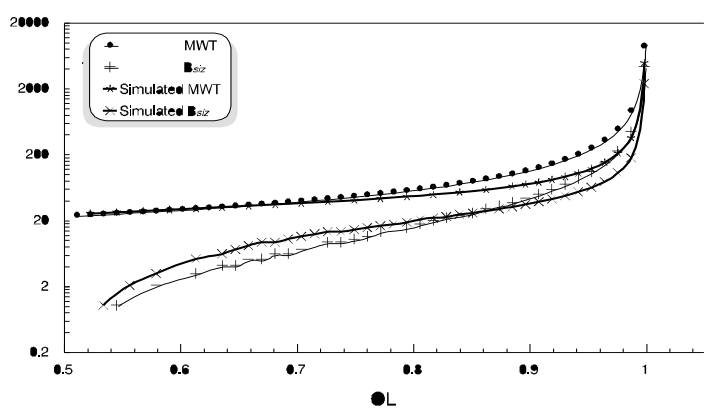

Figure 7 Simulation and Analytical Results

The simulation model works as the server services cells out from the queue by the rate of $352 \mathrm{cell} / \mathrm{ms}$ through the time interval of $0.0625 \mathrm{~ms}$, then no cell serviced through the next interval of $0.0625 \mathrm{~ms}$, and so on. The comparison between the results of the simulation and the queue models is show in Figure 7.

The simulation and analytical results, indicate that as the Offered Load (OL) increase the Mean Waiting Time (MWT) and Buffer Size $\left(\mathrm{B}_{s i z}\right)$ are also increase up to saturation limit. Beyond the saturation limit, MWT and $\mathrm{B}_{s i z}$ rapidly increase due to the large number of cells and queuing delay. The performance study here is to find the effect of the load on the mean waiting time (MWT) and maximum buffer size (MBS). Then finger the maximum load capacity that be carried by the proposed network under multimedia traffic. The simulation programs are implemented in $\mathrm{C}$ language.

\section{B ATM Ring ADM Node Under Multimedia Traffic}

The generated rate of video and data $\left(\mathrm{GR}_{v i}+\mathrm{GR}_{v i}\right)$ is depending on the generated rate of video traffic $\left(\mathrm{GR}_{v i}\right)$, and maximum number of video sources $\left(\mathrm{N}_{v i}\right)$. The ideal Maximum number of voice sources $\left(\mathrm{N}_{v o}\right)$ gets from equations (6) and (7) respectively.

$\mathrm{GR}_{v i}+\mathrm{GR}_{d a}=\left(\mathrm{GR}_{d a}+\mathrm{N}_{v i} \times \mathrm{GR}_{v i}\right)$

$\operatorname{Max} . \mathrm{N}_{v o}=\frac{[352(\text { cell / ms })-\text { transit_rate }(\text { cell / ms })]-G R v i+\text { GRda }]}{\text { GRvo }}$

Figure 8 shows MWT of video and voice versus $\mathrm{N}_{v o}$, and Figure 9 shows MWT of Voice and Data versus $\mathrm{N}_{v o}$, for $\mathbf{R}_{v i}=1.5 \mathrm{Mbps}, \mathrm{R}_{v o}=192 \mathrm{Kbps}, \mathrm{N}_{v i}$ sets to various values such as 10 and $20, \mathbf{M}_{s i z}$ sets to 100 and 300 cells, with $\mu=5$ ms. From Figure 8 and 9, obvious that Voice MWT slightly increases up to saturation limit. Both Video MWT and Data MWT approximately remain constant up to saturation limit. Beyond the saturation limit, Video MWT, Voice MWT, and Data MWT rapidly increase due to the large number of cells of all traffics with a fixed bandwidth. Also the increases in fixed generated cells for video and data traffics, reduces $\mathrm{N}_{v o}$. Obviously that video MWT is smaller than voice MWT and voice MWT is smaller than data MWT. That is because the video traffic has highest priority of service, followed by voice traffic and then Data traffic. 
International Journal of Engineering Sciences \& Emerging Technologies, Feb 2012. ISSN: 2231 - 6604 doi: 10.7323/ijeset/v1_i2_13 Volume 1, Issue 2, pp: 108-117 CIJESET

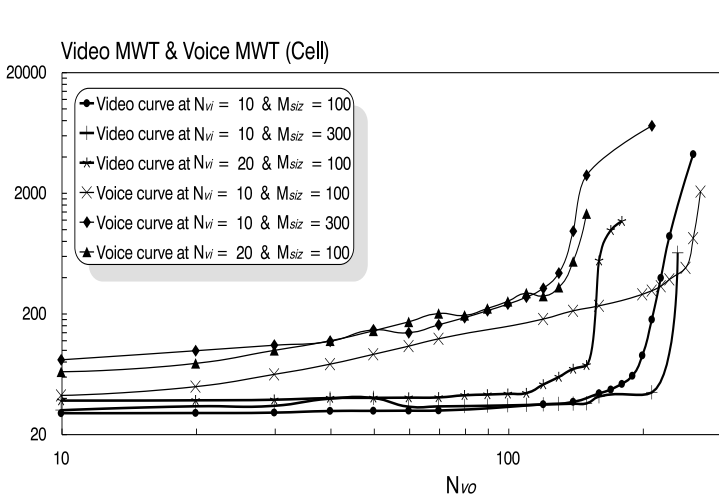

Figure 8 depicts MWT of video \& voice versus $\mathrm{N}_{v o}$ with $\mathrm{R}_{v i}=1.5 \mathrm{Mbps}, \mathrm{R}_{v o}=192 \mathrm{Kbps}$ and $\mu=5 \mathrm{~ms}$.

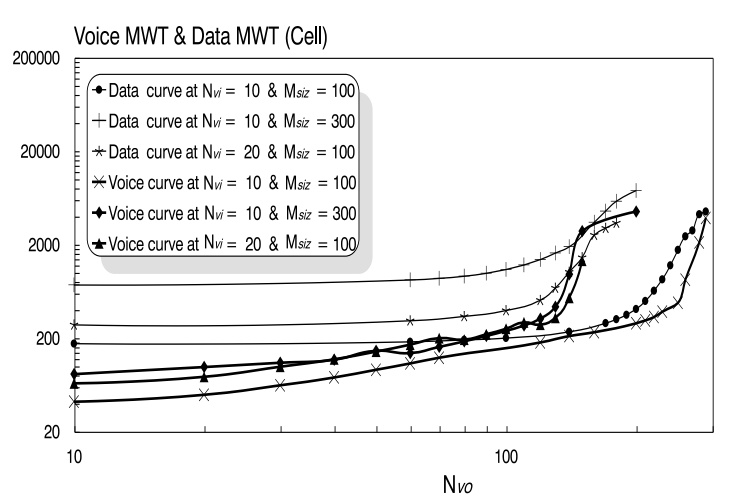

Figure 9 depicts voice MWT \& data MWT versus $\mathrm{N}_{v o}$ with $\mathrm{R}_{v i}=1.5 \mathrm{Mbps}$ and $\mathrm{R}_{v o}=192 \mathrm{Kbps}$ and $\mu=5 \mathrm{~ms}$.

Table 2 shows the different fixed generated rates, the integration of video/data, and corresponding $\mathrm{N}_{v o}$, video MWT, voice MWT, and data MWT.

Table 2

\begin{tabular}{|c|c|c|c|}
\hline Parameters & Case 1 & Case 2 & Case 3 \\
\hline $\mathrm{N}_{v i}$ & 10 & 10 & 20 \\
\hline $\mathrm{M}_{s i z}$ & 100 & 300 & 100 \\
\hline $\mathrm{GR}_{v i+d a}$ & 60 & 100 & 100 \\
\hline Ideal $_{v o}$ & 227 & 149 & 149 \\
\hline $\mathrm{N}_{v o}$ & 210 & 140 & 140 \\
\hline Video MWT & 175.58 & 35.29 & 68.45 \\
\hline Voice MWT & 304.98 & 950.02 & 532.56 \\
\hline Data MWT & 491.49 & 1869.61 & 1003.73 \\
\hline
\end{tabular}

Figure 10 illustrates video MBS and voice MBS versus $\mathrm{N}_{v o}$, and Figure 11 illustrates voice MBS and data MBS versus $\mathrm{N}_{v o}$, for $\mathrm{R}_{v i}=1.5 \mathrm{Mbps}, \mathrm{R}_{v o}=192 \mathrm{Kbps}, \mathrm{N}_{v i}$ sets to various values such as 10 and 20 sources. $\mathrm{M}_{\text {siz }}$ sets to 100 and 300 cells, with $\mu=5 \mathrm{~ms}$. Figure 10 and 11 , indicate that with the increasing of $\mathrm{N}_{v o}$ the voice MBS slightly increases, video MBS and data MBS approximately remain constant up to saturation limit, beyond the saturation limit, video, voice, and data MBS sharply increase because of the increasing of $\mathrm{N}_{v o}$ increases the number of voice cells, resulting in increases in video, voice, and data MBS. The video MBS remains constant for short interval and then increases up to saturation limit.

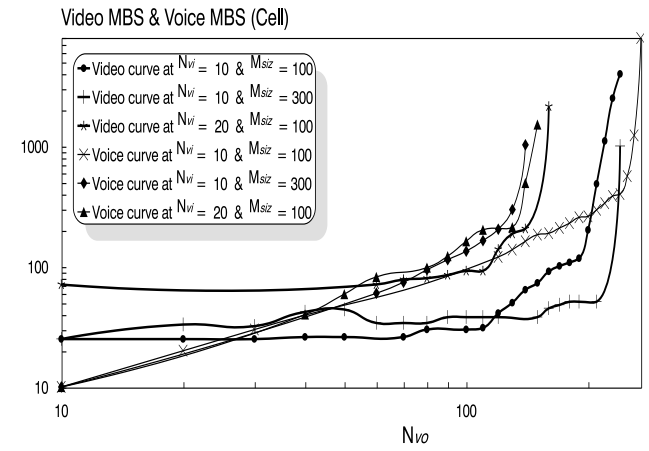

Figure 10 depicts video MBS \& voice MBS versus $\mathrm{N}_{v o}$ with $\mathbf{R}_{v i}=1.5 \mathrm{Mbps}$ and $\mathbf{R}_{v o}=192 \mathrm{Kbps}$ and $\mu=5 \mathrm{~ms}$.

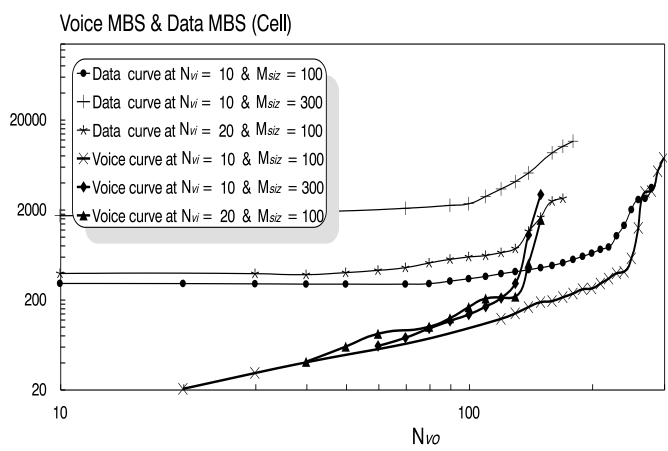

Figure 11 depicts voice MBS \& data MBS versus $\mathrm{N}_{v o}$ with $\mathrm{R}_{v i}=1.5 \mathrm{Mbps}$ and $\mathrm{R}_{v o}=192 \mathrm{Kbps}$ and $\mu=5 \mathrm{~ms}$.

That is because the ratio of each traffic is suddenly change (N.B. the ratio of each traffic ignore the fraction so the ratio increment or decrement suddenly). Table 3 shows the different 
International Journal of Engineering Sciences \& Emerging Technologies, Feb 2012. ISSN: 2231 - 6604 doi: 10.7323/ijeset/v1_i2_13 Volume 1, Issue 2, pp: 108-117 OIJESET

fixed generated rates of the video/data integration, and corresponding $\mathrm{N}_{v o}$, video MBS, voice MBS, and data MBS.

\section{CONCLUSION}

We have presented the performance of VP-Based ring architecture based on ATM network and ADM for carrying multimedia (video, voice and data) traffics. We have proposed a method called a control mechanism, which bears an acceptable characteristic for the integration of video, voice and data traffics on the proposed ATM network. The simulation results clearly show that it is an efficient and simple method, which adapts the ratios of the video, voice, and the data traffics on the network. The simulation results also confirm its efficient to adapt the ratios of all traffics and provides fairness among traffics which depend on the applied offered load of each traffic, it is promising enough.

\section{REFERENCES}

[1] D.Gan. S.Mckenzie, (1999), "Traffic Policing in ATM Networks with Multimedia Traffic: The Super Leaky Buket," Computer Comm., Vol. 22,Issue5, Aril 1999, pp.439-450.

[2] M.Bentall, C. Hobbs, B.C. Turton, (1998), “ATM and Internet Protocol,” Arnold, Paris, 1998.

[3] J.N.Mai. C.K.Tham, W.C.Wong, (1998), “A QoS-Based Hierarchical Routing Algorithm for ATM Networks,” Proc. of IEEE APCC/ICCs'98, Vol1, Nov.1998, pp. 9-13.

[4] W. K. Lai. J.-Y. Tsai, (1999), "A flow Control Scheme on ATM Networks With Max-Min Fairness," Computer Comm. Vol.22, Issue5, April, 1999, pp.543-555.

[5] A. McDysan, D.L. Spohn, (1995),“ATM Theory and Application,” McGraw-Hill Series on Computer Communication 1995.

[6] The ATM Forum Technical Committee, The ATM Forum Traffic Management Specification,V4.0, 1996.

[7] Anupam Roy, Md. Imdadul Islam, and M. R. Amin, (2011), "MMPP+M/D/1 Traffic Model in Video-Data Integrated Service under ATM System ," IACSIT International Journal of Engineering and Technology, Vol. 3, No. 6, December 2011, pp.615-620.

[8] Ming Xiang Guan, Yun Feng Xing, Xue Yuan Wan, (2011),"Multicast Model For Broadband Multimedia Satellites Over ATM Networks," Advanced Materials Research Volumes (204-210), February, 2011, pp.441-444.

[9] L. P Raj Kumar, K. Sampath Kumar, D. Mallikarjuna Reddy, Malla Reddy Perati, (2011), "Analytical Model for Loss and Delay Behavior of the Switch under Self-Similar Variable Length Packet Input Traffic", IAENG Int. J. Computer Science, vol. 38, no. 1, February, 2011, pp. 26-31

[10] Md. Imdadul Islam, M. F. K. Patwary and M.R. Amin, (2011), "Cost Optimization of Alternate Routing Network of M/G/1(M) Traffic", The Mediterranean Journal of Electronics and Communications, vol.6, no. 1, 2011, pp. 190-195.

[11] Vikram Bali, Rajkumar Singh Rathore and Amit Sirohi, Article:, (2010), "Performance Analysis of Priority Scheme in ATM Network," International Journal of Computer Applications 1(13), February 2010. Published By Foundation of Computer Science, pp.26-31.

[12] Cemal Kocak, Ismail Erturk, and Huseyin Ekiz, (2009), "MPLS Over ATM and IP Over ATM Methods For Multimedia Applications," Journal of Computer Standards \& Interfaces, Vol.31, Issue 1, January, 2009.

[13] Wong, Chan, Leung (2009), "Performance evaluation of path optimization schemes for inter-switch handoff in wireless ATM networks," Proc., IEEE MobiCom-98, Dallas, TX, 242-251 (1998) IJNS homepage:http://www.nonlinearscience.org.uk/200 International Journal of Nonlinear Science, Vol.7 (2009), No.2,pp. 189-200.

[14] R. Handel, M. N. Huber, S. Schroder, (2009),"ATM Networks- Concepts, Protocols and Applications,"7e. Pearson Education Ltd; India (2004) IJNS homepage:http://www.nonlinearscience.org.uk/198 International Journal of Nonlinear Science,Vol.7(2009),No.2,pp. 189-200.

[15] J. P. Dubois, and H. M. Chiu, (2005), "High Speed Video Transmission for Telemedicine using ATM Technology,"World Academy of Science, Engineering and Technology 12, 2005, pp. 103-107.

[16] S. H. Lim, M. H. Yaacob, K. K. Phang, T. C. Ling, (2004) "Traffic Engineering Enhancement to QosOSPF in Diffserv and MPLS Networks," IEE Proceedings online Vol. 151, No. 1, February 2004.

[17] Chowdhury, M., Tu, Y. and Pham, T. (2003), "MPEG Traffic Performance via TCP over ATM," in CSITeA 03 : Proceedings of the International Conference on Computer Science, Software Engineering, Information Technology, e-Business and Applications, [CSITeA], [U.S.A.], pp. 128-132. 
International Journal of Engineering Sciences \& Emerging Technologies, Feb 2012. ISSN: 2231 - 6604 doi: 10.7323/ijeset/v1_i2_13 Volume 1, Issue 2, pp: 108-117 OIJESET

[18] Milan Nikolic, (2002) "Performance Measurements of Multimedia Transmissions in IP Over ATM Networks," A THESIS of MASTER OF APPLIED SCIENCE, SIMON FRASER UNIVERSITY, December 2002

[19] A. Alles(2002),“ATM Internetworking,” May 1995. http:/www.cisco.com/warp/public/614/12.html December, 2002.

[20] C. Ling, (2001), “ATM Traffic Monitor,” ENSC 494 Special Project Laboratory, July 2001.

[21] E. Yan, (2001), "Video Transmission over ATM Network Simulation," CMPT 894 Directed Reading, December 2001.

[22] C. Chrysostomou1, A. Pitsillides, F. Pavlidou, (2001), "A Survey of Wireless ATM Handover," Issues. Proc. Of the Int. Symposium of 3G Infrastructure and Services. 2 (3), 2001, pp.34-39.

[23] Anna Hac, Peng, (2001), "A two-phase combined QoS-based handoff scheme in a wireless ATM network," International Journal of Network Management. 11, 2001, pp.309-330.

[24] M. A. Marsan, C. Chiasserini, A. Fumagalli, (2001), "Performance Models of Handover Protocols and Buffering Policies in MobileWireless ATM Networks," IEEE Trans. on Vehicular Technology. 50 (4) 2001, pp. $925-941$.

[25] T.C. Wang, J. W. mark, K.C. Chua, (2001), "Delay performance of voice and MMPP video traffic in cellular wireless ATM network," , IEE Proc. Commun., vol. 148, no. 5, Oct. 2001, pp. 302-309.

[26] Zafar Ali and Arif Ghafoor, (2000), "Synchronized delivery of multimedia information over ATM networks," Magazine Communications of ACM, Volume 43 Issue 11es, Nov. 2000.

[27] Bing Zheng and Mohammed Atiquzzaman, (1999), "Traffic Management of Multimedia over ATM Networks," IEEE Communications Magazine, Vol.37, Issue 1, January 1999, pp. 33-38.

[28] B. Zheng and M. Atiquzzaman, (1998), "Video on Demand Over ATM: System Design and Networking Requirements," Proc. ENCOM'98, Atlanta, GA, June 7-11, 1998.

[29] A. Mehaoua and R. Boutaba, (1998), "Performance Analysis of Cell Discarding Techniques for Best Effort Video Communications Over ATM Networks," Comp. Networks and ISDN Sys., vol. 29, no. 17-18, Feb. 1998, pp. 1999-2019.

[30] B. Vandalore et al. (1999), "Quality of Service and Multipoint Support for Multimedia Applications Over ATM ABR Service," IEEE Communications Magazine, Vol.37, Issue 1, January 1999.

[31] M. Graf, (1997), "VBR Video Over ATM: Reducing Network Resource Requirement Through End System Traffic Shaping," Proc. IEEE INFOCOM '97, Kobe, Japan, Apr. 7-11 1997, pp. 48-57.

[32] M. Krunz and S. K. Tripath, (1997), "Exploiting the Temporal Structure of MPEG-2 Video for the Reduction of Bandwidth Requirement," Proc. IEEE INFOCOM'97, Kobe, Japan, Apr. 1997, pp. 143-50.

[33] Mostafa H. Ammar, Victor O. K. Li, Mehmet Ulema, (1995), "Broadband ISDN : Standards, Switches, and Traffic Management," Computer Networks and ISDN system 27, 1995, pp.1411-1427.

[34] Leonard Kleinrock, (1976), "Queueing Systems" volume II: Computer Applications, John Wiley \& Sons, Inc. , 1976.

[35] T. Y huange and j-L C.Wu, (1994), "Performance Analysis of ATM Switches Using Priority Schemes," IEEE Proc. Comm. Vol.141, No. 4, August 1994, pp 248-254.

[36] Totomu Murase, Hiroshi Suzuki, shohei Sato and Takao Takeuchi, (1991), "A Call Admission Control Schemes for ATM Networks Using a Simple Quality Estimate," IEEE journal On Selected Areas in Communications vol. 9, Dec 1991, pp 1461-1470.

[37] T. Y Huang and j-L C. Wu, (1994) "Performance Analysis of Prioritized State Dependent Buffer Management Schemes in ATM Networks Switches Using Priority Schemes" Computer Networks and ISDN Systems, Vol.27 No. 10, Oct. 1994, pp45-66.

[38] C, Rosenberg, F. Guillemin and R. Mazumdar, (1995), "New Approach for Traffic Characteristics in ATM Network," IEEE Proc. Comm. Vol.142, April 1995, pp87-90.

[39] A. L Roginsky, L A. Tomek and K. J . Christensen, (1997), "Analysis of ATM Cell Loss for Systems with On/Off Traffic Sources," IEEE Proc. Comm. Vol.144, June 1997, pp129-134.

[40] Youngho LIM, john E. Kobza, (1990), "Analysis of a Delay Dependent Priority Discipline in An Integrated Multi-class Traffic Fast Packet Switch," IEEE transaction on comm., Vol.38, May 1990, pp659-665.

[41] Marek Wenik, Osama Aboul Magd and Henry Gilbert, (1992), "Traffic Management for B- ISDN Services," IEEE, Sept,1992, Network pp10-18.

[42] Henry Gilbert, Osama Aboul Magd and Van Phung, (1991), "Developing a Cohesive Traffic Management Strategy for ATM Network," IEEE comm.. Magazine, Oct. 1991, pp 36-45.

[43] Thomas M . Chen, jean Walrand and David G. Messerschmitt, (1989), "Dynamic Priority Protocols Packet Voice," IEEE journal On Selected Areas in communication Vol. 7, June 1989, pp 632-643.

[44] Arthur Y. M. Line and john A. Sylvester, (1991), "Priority Queuing Strategies and Buffer Allocation Protocols for Traffic Control at an ATM Integrated Broadband and Switching System" IEEE journal on Selected Areas in Communication vol. 9, Dec. 1991, pp 1535. 
International Journal of Engineering Sciences \& Emerging Technologies, Feb 2012. ISSN: 2231 - 6604 doi: 10.7323/ijeset/v1_i2_13 Volume 1, Issue 2, pp: 108-117 OIJESET

[45] Hans Kroner, Gerard Hebuterne, Pierre Boyer and Annie Gravery " Priority Management in ATM Switching Nodes " IEEE journal on Selected Areas in Comms . Vol. 9, April 1991, pp 418-427.

[46] T. Ho. Wu, Dennis T. Kong and Richard C.Lau, (1992), "An Economic Feasibility Study for a Broadband Virtual Path SONET/ATM Self-Healing Ring Architecture," IEEE Journal on selected Areas in Communications, vol. 10, no. 9, , Dec.1992, pp. 1459-1473.

[47]T.H. Wu, (1992), "Fiber Network Service Survivability: Architectures Technologies, and Design,"Artech, may 1992.

[48] T. H. Wu and R. C. Lau, (1990), "A Class of Self-Healing Ring Architectures for SONET Network Applications," in proc. IEEE GLOBECOM'90, San Diego, CA, Dec. 1990 , pp. 403.2.1-403.2.8.

[49] T.H. Wu. and M. Burrowes, (1990) "Feasibility Study of a High-Speed SONET Self-Healing Ring Architecture Future Interoffice Fiber Networks," IEEE Communi. Mag., vol28, No.11, Nov. 1990, pp.33-42.

[50] Shinya Nogami, (1991), "Quality Control at The Cell Level and its Characteristics in the ATM Network", Electronics and communications in Japan, part 1, vol. 74, no. 7, 1991, pp.10-21.

[51] E.Khalil, A.El-Sayed, N.Ismal, I.Morsi, (2000), "Control Mechanism For Fairness Among Traffics on ATM Network," Accepted for Publication in 18 ${ }^{\text {th }}$ IASTED Intel. Conf. AI2000, Austria, Feb. 14-17, 2000.

[52] ITU/CCITT,(1991),"H.261:Video CODEC for Audiovisual Services at P X 64 Kbps," Geneva 1990.

[53] International Organization for Standarization (ISO),"MPEG : Coding of Moving Pictures and Associated Audio for Digital Storage Media At up to About 1.5 Mbps", Nov. 1991.

[54] I. Dalgic, and F. Tobagi, (1995), "Constant Quality Video Encoding," IEEE Proceeding ICC'95, Seatle, Washington, , June 1995, pp.1-7.

[55] C. A. Noronha, F. A. Tobagi, (1994), "Evaluation of Multicast Routing Algorithms for Multimedia streams," IEEE ITS94 Proceeding, Rio de Janeiro, Brazil, Aug. 1994, pp.1-8.

[56] P.V.Rangan, S. Kumar, and S. Rajan (1996), "Continuity and Synchronization in MPEG," IEEE J. on Selected Area in Comm., Vol. 14, No. 1, Jan 1996.

[57] P. Wong, and T. Peter (1989), "An Integrated Services Token Controlled Rýing Network," IEEE J. Select. Areas Commun., Vol.7, No.5, June 1989, pp.670-679.

Ehab Aziz Khalil, (B.Sc'78 - M.Sc.'83 - Ph.D.'94), Ph.D. in Computer Network and Multimedia in the Dept. of Computer Science \& Engineering, Indian Institute of Technology (IIT) Bombay-400076, India in July 1994, Research Scholar from 1988-1994 with the Dept. of Computer Science \& Engineering, Indian Institute of Technology (IIT) Bombay-400076, India, M.Sc in the Systems and Automatic Control, Faculty of Electronic Engineering, Minufiya University, Menouf - 32952, EGYPT, Oct. 1983, B.Sc. in the Dept. of Industrial Electronics, Faculty of Electronic Engineering, Minufiya University, Menouf -

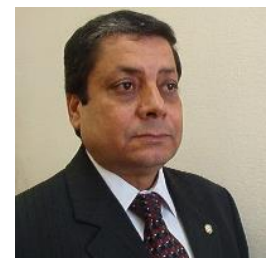
32952, EGYPT, May 1978. Since July 1994 up to now, working as a Lecturer, with the Dept. of Computer Science \& Engineering, Faculty of Electronic Engineering, Minufiya University, Menouf - 32952, EGYPT.. Participated with the TPC of the IASTED Conference, Jordan in March 1998, and With the TPC of IEEE IC3N, USA, from 2000-2002. Consulting Editor with the "Who's Who?" in 2003-2004. Member with the IEC since 1999. Member with the Internet2 group. Manager of the Information and Link Network of Minufiya University, Manager of the Information and Communication Technology Project (ICTP) which is currently implementing in Arab Republic of EGYPT, Ministry of Higher Education and the World Bank. Published more than 85 research papers and articles review in the international conferences, Journals and local newsletter. 